\section{The characteristics of gold films deposited on ceramic substrate}

\author{
Violeta Popescu*, Ioan Vida-Simiti**, \\ Nicolaie Jumate** \\ Technical University of Cluj-Napoca, B-dul Muncii \\ no. 103-105, zipcode 400641, Cluj-Napoca, Romania \\ ${ }^{*}$ Chemistry Department \\ **Materials Science and Engineering Department \\ email: violeta.popescu@chem.utcluj.ro
}

\begin{abstract}
A large quantity of gold (approximately 10 tonnes yearly) is consumed, all over the world, just to decorate ceramic and glassware. Due to their advanced chemical stability gold films are used for different high technology applications. The technologies for obtaining the best "liquid bright gold" were intensively studied, but the quality of the decor coatings (films) were empirically assessed. We proposed a scientific investigation of the characteristics of gold films, deposited on ceramic substrates, from "liquid bright golds". The composition of the film has been determined by EDS (Energy Dispersive X-ray Spectrometry). The distribution of the elements was determined at the surface of the film and in cross-section. The surface distribution of the elements was uniform. The diffusion process of the film into substrate and the migration of the substrate elements at the interface region and into the film have been highlighted.

The morphology of the film was studied by SEM microscopy. The grain size varied between $0.05-2 \mu \mathrm{m}$ as a function of the film composition. The major phases from the film and interface were evidenced by X-ray diffraction. The film consisted of crystalline gold. At the interface region a solid solution of $\mathrm{Au}-\mathrm{ZrSiO}_{4}$ was identified. Other phases were in amorphous state. The reflection spectra of the films were recorded from optical properties, using a mirror gold as standard, for comparison. The film with the smaller particle size reflected the UV - VIS wavelengths in the same way as a gold mirror. The adherence of the film on the substrate can be explained by the formation of an interfacial layer from solid solution $\mathrm{Au}^{-} \mathrm{ZrSiO}_{4}$ and by diffusion processes.
\end{abstract}

\section{Keywords}

Liquid bright gold, Gold films, EDS spectra

\section{Introduction}

The aim of this paper is to report new data about the composition, morphology, structure, optical properties of thin gold film deposited on ceramic substrates from "liquid golds", and the study of the interfacial region, by SEM-EDS microanalysis. For the first time in open literature the crosssection of film - substrate composition was determined, highlighting the compounds formed on the interfacial region, which play an important role in the adhesion mechanism.

Liquid gold or "liquid bright gold" are basically solutions of gold in organic solvents which, when applied to a smooth glossy surface, usually glass or ceramic, and heated in air to burn off the organic constituents, produce a specular mirrorlike film of gold (1-3). The history of liquid gold, their uses in the decoration of different types of glassware and the methods of application employed are presented by Papazian (2), Nixon (3) and Landgraf (4).

"Liquid bright golds" contain small amounts of organic compounds of certain other metals, such as Rh, Bi, Cr, etc. and a vehicle or solvent therefore. The gold compound may be resinates, terpene mercaptides or other organic sulphides.

For obtaining bright, continuous, adherent films, except gold organic compounds, small amounts of other noble metals such as Rh, Pd, Os, Ir, Pt, Ag and minimum two fluxes, such as: Li, Na, K, Cu, Ca, Sr, Mg, Ba, Zn, B, Al, Bi, Ti, Si, Mo, Fe, $\mathrm{Cr}, \mathrm{Ni}, \mathrm{Ge}, \mathrm{Sn}, \mathrm{Pb}, \mathrm{V}$, etc. are added in the products, in adequate concentrations (5). The added elements have an important role in film formation, influencing the morphology, the adherence, the colour hues and the resistance to abrasion (6-11).

Bismuth (III) oxide in adequate concentration prevents structural agglomeration (12) and contributes to adherence. The presence of rhodium oxide $\left(\mathrm{Rh}_{2} \mathrm{O}_{3}\right)$ formed by pyrolysis, on the grains boundaries of the gold particles, also prevents the agglomeration by diffusion of one particle to another when they are in contact, limiting their size and promoting the formation of bright films $(2,13,14)$.

The composition of "liquid bright gold" varies as a function of the proposed substrate and the future applications. Electrical and optical properties, wear resistance and adherence are important for technical applications. Base metals ensure reaction bonding of gold film to substrate $(2,15,16)$.

The literature abounds with data regarding the compositions for "liquid bright gold" used for thin films deposition on ceramic or glass substrates, (1,5-10), but there are only a few published data related to the composition and the characteristics of the formed films even if there is plenty of data held by Liquid gold manufacturers, that is not published. 
Recently, a very interesting paper presented the results on the investigation of gold/ceramic and gold/glass interfaces (11). The authors determined the composition, morphology and optical properties of gold films deposited on ceramic substrate. The paper discusses the mechanism of the adherence of the gold to the substrate by diffusion processes and the physico-chemical interactions. The migration of gold into the glass takes place even at temperatures as low as $370^{\circ} \mathrm{C}(17)$. The diffusion coefficient of gold in amorphous silica, between $800-1200^{\circ} \mathrm{C}$ is $1.710^{-17} \mathrm{~cm}^{2} \mathrm{~s}^{-1}$ (18). Bauer et al (19) explain the adhesion of gold by formation of Au-Si bonds.

Nguyen (20) explains the adherence of gold films obtained by thermal evaporation on ceramic (alumina $\mathrm{Al}_{2} \mathrm{O}_{3}$ ) substrates by the formation of $\mathrm{AlAu}_{2}$ and $\mathrm{Al}_{2} \mathrm{Au}$ compounds during thermal treatments applied to formed films for 3 hours at $500^{\circ} \mathrm{C}$. Metal atoms deposited on the ceramic surface, react with free aluminium to form the AlAu compound. The penetration of gold in the ceramic is weak for as formed films and only a small amount of compound would be formed. The adhesion of the gold layer to the substrate is poor. Upon heating at $500^{\circ} \mathrm{C}$, the diffusion of gold becomes important and the heat treatment enables several processes to occur. First, the AlAu compound is formed in the middle part of the interface. Next, under favourable thermodynamic conditions, a second species of compound, $\mathrm{AlAu}_{2}$ appears together with $\mathrm{AlAu}$ in the innermost layers (the eutectic temperature of AlAu is $624^{\circ} \mathrm{C}$ ). Finally, gold oxide is created in these layers by the oxidation of the diffused gold atoms. The adhesion is enhanced after treatment by the formation of new compounds including the oxide.

During the firing of liquid gold, or thermal treatments applied to thermal evaporate gold a migration phenomenon of elements to the interface film - substrate, or even in the film, takes places due to a mutual solubility of the film and the substrate $(11,12,17,20,21)$.

Marcu et al (10) explained the adherence of the gold film on the ceramic substrate by chemical reactions between elements from film (Mg) and those present in the substrate (glaze) (Si, Al), with the formation of an interfacial compounds such as: spinel oxide $-\mathrm{MgAl}_{2} \mathrm{O}_{4}$ and $\mathrm{MgSiO}_{3}$.

Some optical properties, respectively the reflectance of the gold films, deposited on glass were reported by Papazian (2). For the wavelength between $0.4-0.8 \mu \mathrm{m}$ it varies between $33-97 \%$ and $71-100 \%$ for $1-3 \mu \mathrm{m}$. I. Pop et al. (15) studied the gold film as thick as $80 \mathrm{~nm}$, deposited on glass (8) and obtained values of this parameter of about $98 \%$ in the all IR range (1-25um).

The high thermal and chemical stability, soldering properties of noble metals films, as well as optical or electrical properties made possible a large variety of applications other than decorative ones, in automotive (22), military (23), chemical industry, biochemical sensors (24-28) and as contacts for humidity (29) or temperature (30) sensors.

\section{Experimental Details}

The liquid bright gold was applied with a brush on glazed white faience tiles, and then fired in an oxidizing atmosphere for 20 minutes at $750^{\circ} \mathrm{C}$. All liquid gold samples were appropriate for ceramic decoration.

The morphology of Au films was characterized using Scanning Electron Microscopy (SEM) (Jeol JSM -5600LV). The EDS spectra for the film after firing were recorded. An elemental quantitative analysis of the determined elements was made with a X-ray spectrometer, coupled to the electron microscope - Energy Dispersive Spectrometer (EDS), with a Si(Li) detector.

The identification of the film - substrate phases was made by X-ray diffraction, with a Dron 3 diffractometer, with a CuK $\alpha$ radiation. The reflection for VIS (350-800 nm) was determined with a Spekol Spectrophotometer specially adapted for this purpose.

Five samples of films deposited from liquid bright gold were investigated. The first three samples were deposited from commercially available gold compounds, no information relating to the samples was given due to confidentiality). Samples no. 4 and 5, had known composition, prepared by the authors, starting from the compounds described in the patents $(8,10)$. Samples 4 and 5 contain: gold, palladium and rhodium terpene sulphide sulpho-resinates, copper, bismuth, chromium resinates and vanadium butyl-vanadate.

\section{$3 \quad$ Results and Discussions}

\subsection{The Composition and the Distribution of the Chemical Elements in the Gold Layer and on the Gold-Substrate Interface}

EDS spectra, presented in figure 1, for films and for the ceramic substrate were registered in order to determine the composition of the film.

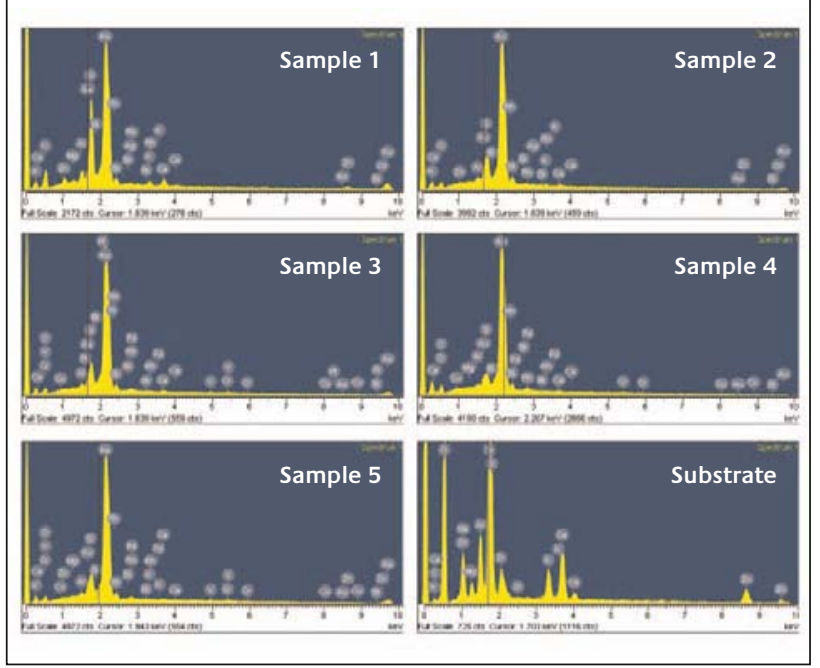

Figure 1

EDS spectra for gold films and for the substrate 
Table 1

The composition of gold films and for substrate

\begin{tabular}{|c|c|c|c|c|c|c|c|}
\hline \multirow[t]{2}{*}{ No. Crt. } & \multirow[t]{2}{*}{ Element } & \multicolumn{5}{|c|}{ Chemical composition of the film [\%] } & \multirow{2}{*}{$\begin{array}{c}\text { Chemical composition } \\
\text { of the substrate [\%] }\end{array}$} \\
\hline & & Sample 1 & Sample 2 & Sample 3 & Sample 4 & Sample 5 & \\
\hline 1. & O & 16.99 & 7.34 & 13.00 & 13.99 & 4.93 & 49.76 \\
\hline 2. & $\mathrm{Mg}$ & 0.38 & - & - & $0.20^{*}$ & $0.11^{*}$ & 1.00 \\
\hline 3. & $\mathrm{Al}$ & 1.31 & 0.58 & 0.19 & $0.29^{*}$ & $0.57^{*}$ & 3.44 \\
\hline 4. & $\mathrm{Si}$ & 9.35 & 4.63 & 1.58 & $1.65^{*}$ & $3.61^{*}$ & 24.88 \\
\hline 5. & K & 0.92 & 0.50 & - & - & $0.20^{*}$ & 2.56 \\
\hline 6. & $\mathrm{Ca}$ & 1.68 & 0.56 & - & $0.31^{*}$ & $0.56^{*}$ & 5.52 \\
\hline 7. & $\mathrm{Zn}$ & 2.76 & 1.07 & - & - & $0.08^{*}$ & 7.08 \\
\hline 8. & $\mathrm{Na}$ & - & - & - & - & - & 1.27 \\
\hline 9. & $\mathrm{Zr}$ & - & - & - & - & - & 4.49 \\
\hline 10. & Rh & 0.67 & 1.07 & 1.24 & 0.76 & 0.66 & - \\
\hline 11. & $\mathrm{Pd}$ & - & - & 0.20 & 1.84 & 1.74 & - \\
\hline 12. & Pt & - & - & - & 0.47 & 0.21 & - \\
\hline 13. & $\mathrm{Ag}$ & 0.87 & 1.00 & 1.27 & - & - & - \\
\hline 14. & $\mathrm{Cr}$ & - & 0.12 & - & 0.27 & 0.31 & - \\
\hline 15. & V & - & - & - & - & 0.31 & - \\
\hline 16. & $\mathrm{Cu}$ & - & - & - & 0.28 & 0.14 & - \\
\hline 17. & $\mathrm{Bi}$ & 0.94 & 4.08 & 3.71 & 1.85 & 1.26 & \\
\hline 18. & $\mathrm{Au}$ & 64.13 & 79.18 & 78.81 & 78.55 & 85.52 & - \\
\hline
\end{tabular}

The compositions of the formed films are presented in Table 1, in comparison with the substrate.

At EDS analysis, because the formed film is very thin (thickness smaller than $0.1 \mu \mathrm{m}$ ) and porous, the electrons can pass through the layer and penetrate into the sample more than $500 \AA$, resulting in X-ray spectra from the interaction of

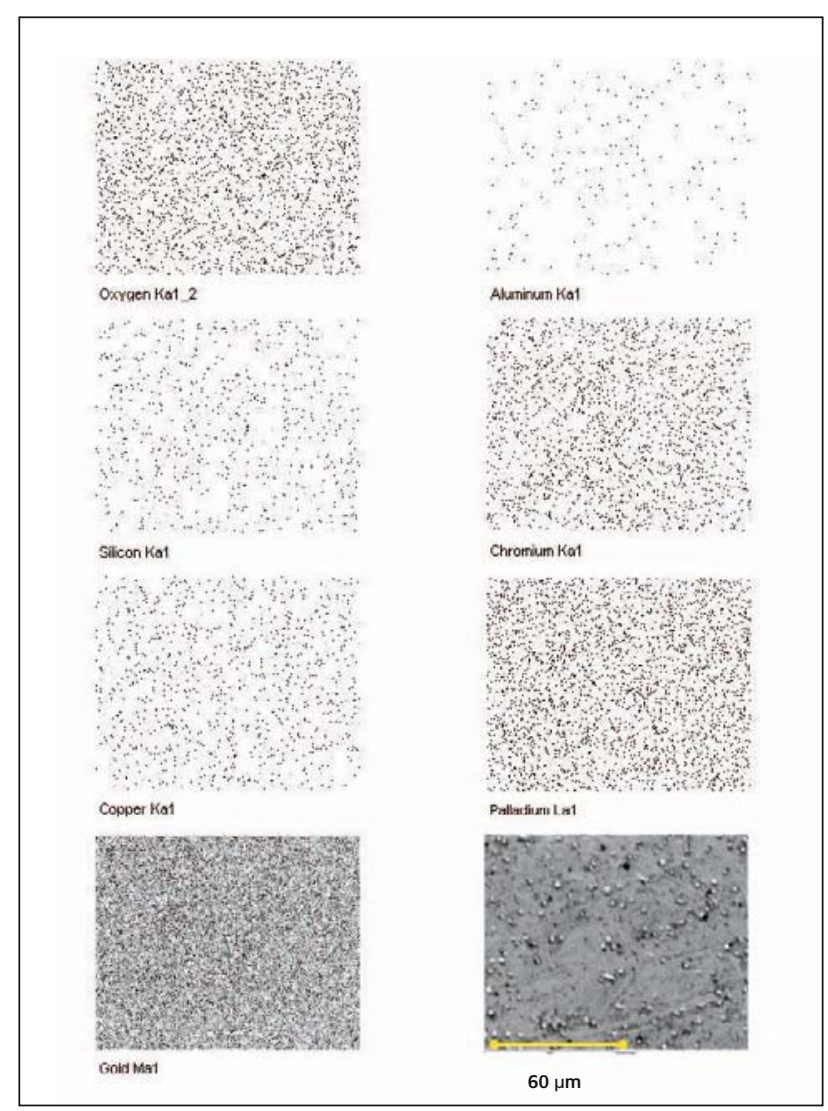

Figure 2

X-ray maps of O, Al, Si, Cr, Cu, Pd, and Au for sample no. 5 the electrons with the interfacial region. Because the substrate is the same, for all studied samples, the error for the determined composition is a systematical one in the same way. The elements from the substrate appear in the table 1 (elements noted with * for samples 4 and 5).

The presence of elements from the substrate in EDS spectra could be due to the fact that, during the firing, a migration phenomenon of those elements to the interface film - substrate, or even in the film, takes places due to a mutual solubility of the film and the substrate $(11,12,17,20,21)$. The migration of the fluxes to the gold film - ceramic interface could explain the fact that some fluxes added by us in the gold compound ( $\mathrm{V}$ in sample 4 ) and $\mathrm{Ni}$ in sample 5, do not appear on the EDS spectra. The interdiffusion of gold and substrate elements during thermal treatment was also discussed by Nguyen (20).

In Figure 2 the surface EDS distribution of a part of the elements in the film for sample no. 5 is presented. One can remark a uniform distribution for all elements, which attests a good quality of formed film, respectively continuity and homogeneity.

\section{The Determination of Interfacial Regions Composition}

The interfacial layer generated during the formation of the film contains, mainly, Au-Si-Zr.

The distribution of $\mathrm{Zr}, \mathrm{Si}, \mathrm{Au}$, in the interfacial layer is presented in Figure 3. Diffusion of the gold in glaze is observed. Si and Zr migrate toward the surface of the film. In the ceramic glaze Si has a uniform distribution.

The segregation of $\mathrm{Zn}$ and $\mathrm{Zr}$ (elements introduced in ceramic glaze for whitening) at the interface Au/substrate during the formation of the film was observed also by 


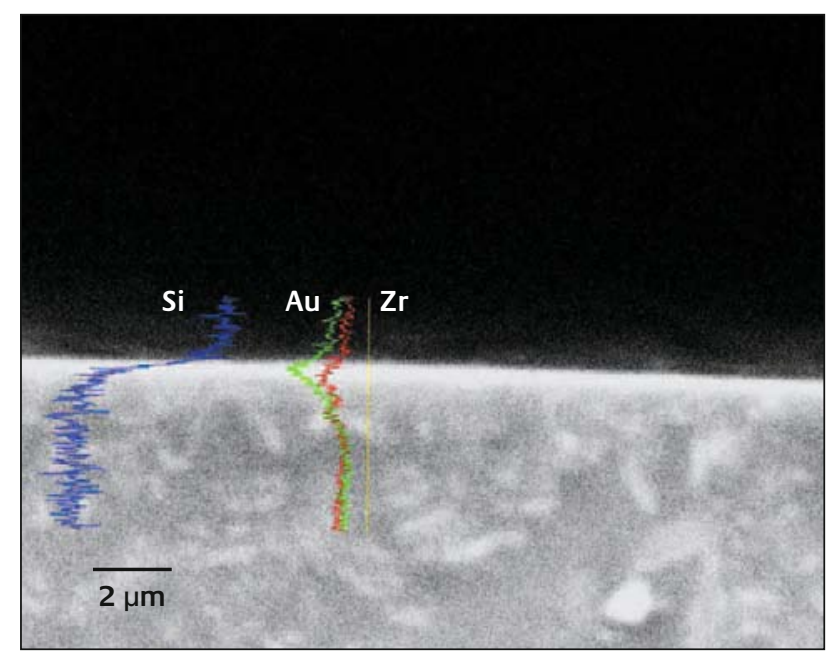

Figure 3

$X$-ray linescan for $A u, Z r$, and Si in the gold film cross section (sample no. 5)

Darque-Ceretti et al (11), concurrent with the diffusion of small quantities of metal in the substrate.

The migration processes which takes place during the film formation is confirmed by the presence of some elements, such as $\mathrm{K}, \mathrm{Mg}, \mathrm{Ca}, \mathrm{Al}$, Si in some of the analysed films (table 1), even if in samples no. 4 and 5 those elements have not been introduced in the gold compound. The migration of the elements took place due to some diffusion phenomena. Thus we explain the adherence of gold film on the ceramic substrate.

The $\mathrm{Zr}$ wave has been evidenced by $\mathrm{X}$-ray diffraction as crystalline zirconium silicate (zircon) - $\mathrm{ZrSiO}_{4}$, as it will be shown in chapter 3.3.

In Figure 4, the EDS distribution spectra of O, Ca, Al, K, Zn, $\mathrm{Mg}, \mathrm{Si}$, and $\mathrm{Au}$ are presented for a cross section of the filmsubstrate.

The migration of the elements from the substrate (Ca, Al, $\mathrm{Mg}, \mathrm{Zn}, \mathrm{K}, \mathrm{Si}$ ) into the gold film takes place. Gold also

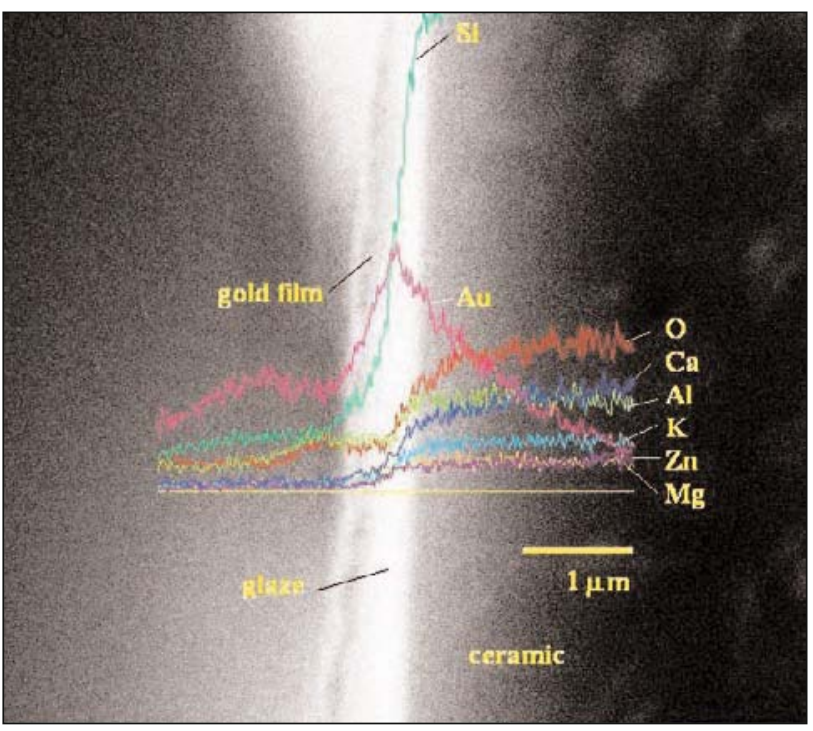

Figure 4

$X$-ray linescan for $O, C A, A L, K, Z N, M g$, Si, and $A u$ in the gold film cross section (sample no. 5) migrates deeply into the glaze and ceramic substrate.

\subsection{The Morphology of Deposited Layer}

Although the films look uniform, at macroscopic level, the SEM electronic micrographs reveal that the layers have a granular morphology.

The deposited layers have a crystalline structure and are formed from granular crystallites of different sizes, which are formed by heterogeneous nucleation.

In Figures 5 a, b and c the micrographs for sample 1 (a), 4 (b) and 5 (c) are presented. The distribution of the grains is uniform. The deposited layer; have porosity depending on the chemical composition, at the same deposition parameters.

The grain sizes range from $0.3-0.8 \mu \mathrm{m}$, for sample no. 1 . Large crystallites is observed, because there were a small number of nucleation centres when the film was formed, and the growth rate rapid. On the other hand, the smaller concentration of $\mathrm{Bi}$, promotes the formation of larger grains (12).

The grains for sample 4 are much smaller, size between 0.05 to $0.1 \mu \mathrm{m}$, because of the presence of larger quantities of $\mathrm{Bi}$. The nucleation centres number was large, and the growth rate smaller.

The greater concentration of Rh in sample 4 also favours the formation of smaller grains (2). The difference between sample 1 and 4 could be also explained by the presence of $\mathrm{Pd}$, Pt and $\mathrm{Cu}$ in sample 4. We assumed that these metals play the same role in the film formation, as Rh (2) and Bi (12), facilitating the formation of continuous highly reflective gold films.

For sample 5 (Figure $5 c$ ), one observes a continuous phase at the surface of which formations with dimensions of $1 \mu \mathrm{m}$ are uniformly distributed. Isolated grains of $4-5 \mu \mathrm{m}$ can be observed. The presence of larger grains in the film could be explained by the decreasing concentration of $\mathrm{Bi}, \mathrm{Rh}, \mathrm{Pd}, \mathrm{Pt}$

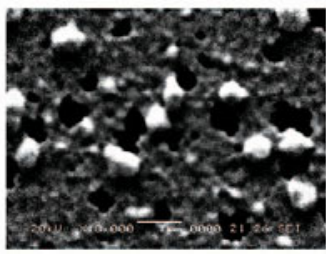

a.

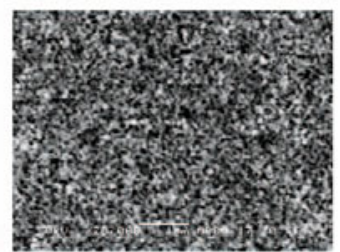

b.

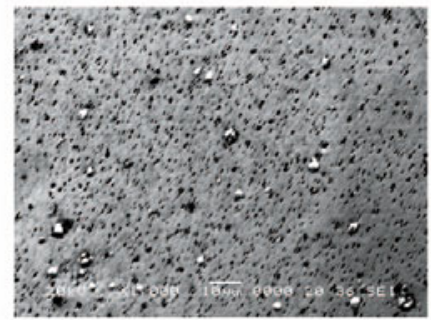

C.

Figure 5

Backscattered electron image for samples no: 1 (a), 4 (b) and 5 (c) 


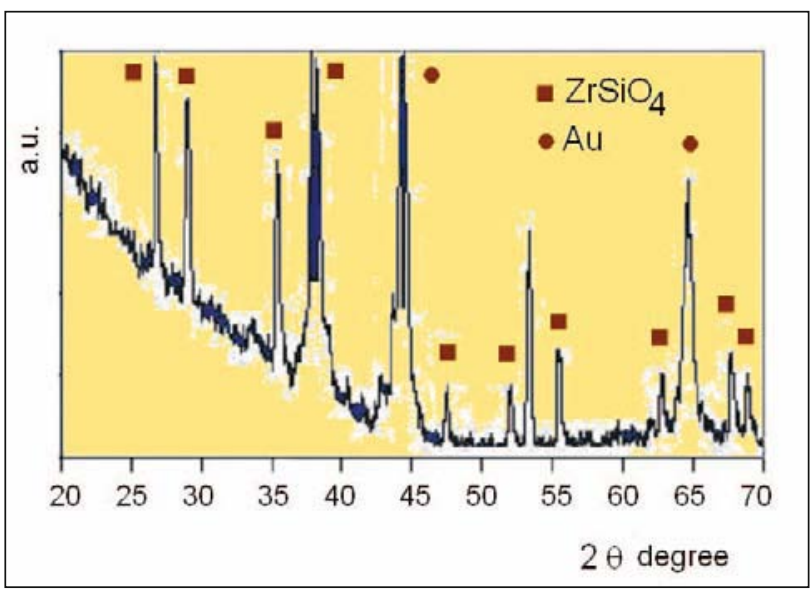

Figure 6

X-ray diffraction spectrum for sample no. 4

and Cu. At macroscopic level film no. 5 is continuous, uniform and bright.

The presence of Rh in the organic gold compound is not sufficient to obtain fine grains of gold. Because sample 4 contains the largest amount of Rh, Pd, Bi and Pt, it seems that those elements have a synergetic effect on the formation of a film with the smallest grain sizes.

The larger grains correspond to sample 5 which contains smaller concentration of elements which play the role of so called oxide precursor (Rh, Pd, Bi, and Pt) (30).

\subsection{X-ray Diffraction Analyses}

In Figure 6 , the X-ray diffraction pattern for sample 4 is presented.

X-ray diffraction of the gold layer shows that this layer has a crystalline structure. The diffraction lines of gold are wide at semi-heights, that indicates that the granular crystalline formations have a size of about $1000 \mathrm{~nm}$. The crystalline grain size, D was determined using Debye-Scherrer relationship:

$$
\mathrm{D}=\frac{0.9 \lambda}{\mathrm{B} \cos \theta}
$$

where: $\mathrm{D}$ is the average size of the crystallites, $\mathrm{B}$ can be deduced from the lower full width at half maximum, $\lambda$ is the $X$-ray wavelength $\left(\lambda_{\text {CuK } \alpha}=1.54182 \AA\right)$ and $\theta$ is the Bragg angle.

The used $\mathrm{X}$-rays for analysis have a penetrating capacity of microns, passing through the analysed layer, giving diffraction signals from the substrate.

In the diffraction spectrum the lines from gold and for $\mathrm{ZrSiO}_{4}$ were identified, which indicates that those phases are crystalline.

The remaining phases from layer - substrate do not appear on the XRD pattern due to concentrations smaller than $3-4 \%$. From chemical analysis (Table 1 ) one observes that $\mathrm{Si}$ is the major compound (except Au and O), but its lines do not appear in the diffraction spectrum as crystalline $\mathrm{SiO}_{2}$ compound. These results indicate that $\mathrm{SiO}_{2}$ is in vitreous phase (amorphous).

However, we mention that $\mathrm{Zr}$ does not appear in the film

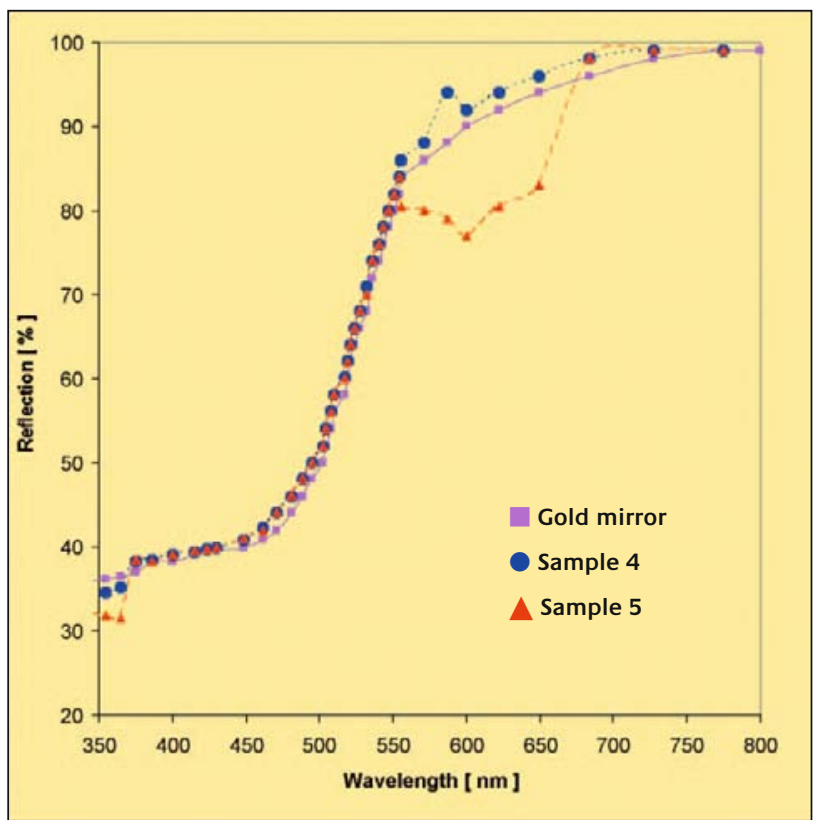

Figure 7

Reflection spectra for a gold mirror and for gold films

composition (Table 1), other than in the substrate. This indicates that $\mathrm{Zr}$ is localized in the interfacial region, responsible to the adherence of the film.

According to obtained results one can conclude that the gold and $\mathrm{ZrSiO}_{4}$ from the interface gold/substrate forms a solid solution.

\subsection{Considerations Regarding the Adherence of the Film to the Substrate}

During pyrolysis chemical reactions between the elements from the film and those from the substrate could take place $(10,14,20)$, leading to the formation of interfacial compounds, which assure a good adherence of the film to the substrate.

From the data obtained by investigating the film composition we highlighted the mutual migration of elements from substrate in the interfacial region or in the film and those from film in the substrate. The bond of the film on the substrate was achieved by the new formed interfacial region $(10-12,17,20,21)$ consisting of oxide compounds coming from liquid gold compounds and those from the glaze and silicates and Al-Au compounds (20).

By X-ray diffraction analysis it was shown that gold has a crystalline structure. The presence of $\mathrm{Zr}$ in the interfacial region as $\mathrm{ZrSiO}_{4}$ in mixtures with gold leads to the formation of a layer consisting of the solid solution of those two phases, having an important role in achieving the adherence of the film on the substrate. The adhesion mechanism is obviously of physical nature.

The adherence of sample 4, determined by us, by soldering a copper wire on the film, and measuring the tensile force to remove the film (12) was 7.4 MPa, comparable with those of Au-Pt paste, deposited on ceramic substrate, which is of $8.4 \mathrm{MPa}$ (13).

All studied films passed the tests regarding acid (acetic acid) and alkali $\left(\mathrm{Na}_{2} \mathrm{CO}_{3}\right)$ resistance (6). The quality of the 
films was not affected by treating them with a solution containing $4 \%$ acetic acid at room temperature, for 24 hours, or by boiling for 2 hours at $100^{\circ} \mathrm{C}$ in solutions containing $0.5 \% \mathrm{Na}_{2} \mathrm{CO}_{3}$.

Liquid gold is mainly used for tableware glazes decoration. Because acetic acid is the main substance contained by vinegar, the stability of formed films is important because vinegar is often used in food preparation. Sodium carbonate is an agent for tableware glazes cleaning. Above mentioned tests are imposed by the quality control normative for gold decorated tableware in Romania.

Adhesion of metal to ceramic is also a consideration in porcelain to dental gold bonding and in brazing of metal to ceramic joints. All use similar additives (Sn, In, Ge, etc) to promote adhesion of the metal film.

\subsection{Electromagnetic wave Reflection of Gold Films}

Optical behaviour of a material could be an important quality to the application of electrical field of electromagnetic waves.

Radiations that reach the surface of a metal undergo reflection and absorption processes.

Under the influence of an electric field of an electromagnetic wave, free electrons from the metal enter into forced oscillatory movement, constituting (generating) electrical current, and a part of the energy of the wave is dissipated in the metal by Joule effect. Electronic gas degenerated from the metal could be considered as a quantum plasma, which oscillate under the action of the electromagnetic wave. The quantum of those oscillations cold be assimilated to some quasi-particles, named plasmons and could explain the optical complex phenomena such as reflection and refraction from the surface of the metals.

The determination of the reflection coefficient was made with a spectrophotometer in the range of $350-800 \mathrm{~nm}$. The variation of reflection coefficient (R) as a function of the wavelength $(\lambda)$ was studied through comparison with a standard, gold mirror, made from 99.99\% Au. In figure 7, the spectra for samples 4 and 5 are presented.

The layer no. 5 absorbs 15-20\% of the electromagnetic waves in a window between $550-700 \mathrm{~nm}$, probably due to the formation of some solid solutions or intermetallic compounds of metallic elements added as fluxes and the major phase (gold), which have other reflection coefficients. The obtained data are comparable with those reported by Papazian (2).

One can observe that the layer no. 4 reflects the electromagnetic wavelengths in the same way with the standard mirror gold. This behaviour can be explained by the greater content of Rh, Pd and Cu (see Table 1).

\section{Conclusions}

Gold layers with thickness ranged between 0.1-2 $\mu \mathrm{m}$ obtained by pyrolysis of organic compounds have a granular structure, evidenced by electronic microscopy (SEM). After analysing 5 samples of gold films we concluded that:

- The films containing $\mathrm{Bi}, \mathrm{Pd}, \mathrm{Pt}, \mathrm{Rh}$ and $\mathrm{Cu}$ in greater concentration have a very fine microstructure with grains ranged between $0.05-0.1 \mu \mathrm{m}$, in comparison with the one without Pd (sample 1) whose grain sizes ranged between $0.3-0.8 \mu \mathrm{m}$.

- The fluxes added play an important role in the transport phenomena, which takes place during film formation.

- The elements from fluxes migrate towards the film substrate interface (glazed ceramic),

- The elements from the substrate (Al, Si, Ca, Mg) migrate from the substrate towards the surface of the film.

- The adherence of the film on the substrate can be explained by the formation of an interfacial layer from solid solution $\mathrm{Au}-\mathrm{ZrSiO}_{4}$ and by diffusion processes.

- Due to their very good adherence and electrical conductibility we applied the gold film to the achievement of electrical contacts for temperature and humidity sensors, on the bases of PbS thin film $(29,30)$.

This research was supported by a Grant from CNCSIS - THE NATIONAL UNIVERSITY RESEARCH COUNCIL, contract no. 33385/2004, Theme no. 63, CNCSIS code: 338, financial support offered by Romanian Ministry of Education and Research.

\section{About the authors}

Associate Professor Violeta Popescu completed her PhD degree with Professor Gheorghe Marcu at the University Babeş-Bolyai from Cluj-Napoca (Romania) in 2000. From 1981 to 1998 she has been at "The Chemistry Institute Raluca Ripan” from Cluj-Napoca, as researcher. Between 1998 2002 she has been a reader, and since 2002 till now an associate professor at Technical University of Cluj-Napoca, at Chemistry Department of Materials Science and Engineering Faculty. Her fields of research interest are: the realization of laminar composites based on noble (Au), commune (Cu, Ni), and semiconducting (sulphides) films on nonconducting substrates (glass, ceramic and plastic materials) with applications in optoelectronics, electronics, aero-space industry, military technique and industrial design. She is author of more than 40 scientific papers, published in international and national journals such as Thin Solid Films, Materials Science and Engineering, Materials Letters, Revue Romaine de Chimie, Revista de Chimie, etc., and 25 papers published in international and national Conference Proceedings. She has 8 years teaching experience in undergraduate and postgraduate departments. She teaches courses of Inorganic Chemistry, Environmental Chemistry, Polymer Materials and Organic Matrix Composites. She is author of 11 books, most of them courses and laboratory guides.

Professor Ioan Vida-Simiti completed his PhD degree with 
Professor dr. eng. Attila Palfalvi at the University of ClujNapoca Cluj-Napoca (Romania) in 1985. Since 1995 he is professor at Technical University of Cluj-Napoca, at Materials Science and Technology Department from Materials Science and Engineering Faculty. From 15 March 2004 he is the dean of Materials Science and Engineering Faculty. He is a member of Rumanian Society of Powder Metallurgy, President of Technical Comity of Standardization in Powder Metallurgy (Romania). His fields of research interest are: Powder Metallurgy and Composite Materials. He is author of more than 150 scientific papers, published in international journals (such as Powder Metallurgy International, Journal of Optoelectronics and Advanced Materials), national journals and Conference Proceedings. He has 30 years teaching experience in undergraduate and postgraduate departments. He teaches courses in Powder Metallurgy, Composite Materials, and Processing Materials and is author of 11 books.

Associate Professor Nicolaie Jumate completed his $\mathrm{PhD}$ degree with Professor PhD Eugen Bicsak at Technical University of Cluj-Napoca (Romania) in 2001. From 1979 to 2005 he has been at Technical University of Cluj-Napoca. Since 2002 he is associate professor at Technical University of Cluj-Napoca, at Materials Science and Technology Department from Materials Science and Engineering Faculty. His fields of research interest are: Materials science, Electron microscopy, $\mathrm{X}$ ray diffraction, Powder metallurgy. He is author of more than 100 scientific papers, published in international and national journals, and Conference Proceedings. He has 33 years teaching experience in undergraduate departments. He teaches courses of Crystallography, Welding Processes, Structure Investigation Methods, Materials for Electronics and electro-techniques. He is author of 2 books.

\section{References}

1 L. Caban, F.L. Reusche, US Patent, 3,018,191, 1962

2 A.N. Papazian, Gold Bull., 1982, 15 (3), 81

3 R. Nixon, Glass, 1984, 61 (2), 47

4 G. Landgraf, Gold. Progress in Chemistry, Biochemistry \& Technology, chapter 6, Gold in Decoration of Glass \& Ceramics, Edit. H. Schmidbaur, 1999, publ. John Wiley \& Sons Ltd

5 G. Landgraf, P. Wenzel, S. Wissel, EP 1160225 A2, 2001

6 Y. Ryuta, S. Masato, EP 0719747 A2, 1995

7 Patricia, Ann Marsh, WO 01/40392 A1, 2000

8 R. Ripan, Gh. Pop, Rom. Patent, 55816, 1970

9 I. Pop, PhD thesis, Babeş-Bolyai University, Chemical Technology Faculty 1981, p. 68

10 Gh. Marcu, Gh. Pop, I. Pop, Rom. Patent, 59653, 1975

11 E. Darque-Ceretti, D. Helary, M. Aucouturier, Gold Bulletin, 2002, 35, 118

12 G. Paulson, Interface Phenomena and Adhesion of Gold Thin Films on Glass, Ph.D Thesis, Xerox University Microfilms, Ann Arbor. Michigan, USA, p. 22, 36, 1975
14 A.A. Milgram, J. Electrochem Soc., 1971, 118, 287

15 I. Pop, C. Naşcu, V. Ionescu, E. Indrea, I. Bratu, Thin Solid Films, 1997, 307,240

16 W.S. Rapson, Gold Bull., 1979, 12 (3), 108

17 A. Katz, S. Nakahara, M. Geva, J. Appl. Phys, 1991, 70, 7343

18 G.H. Frischat, 'Ionic diffusion in oxide glasses', Trans Tech. Publications, Aedermannsdorf, 1975

19 R.S. Bauer, R.Z. Bachrach, L.J. Brillson, Appl. Phys. Lett., 1980, 37, 1006

20 M. Mattox, Sandia Corp. Reprint SC-R-65-997, 1966

21 G.B. Fefferman, US Patent,3,653,946, 1972

22 J.R. Norton, Proc. 45th Ann. Symp. on Frequency Control, 1991

23 G. Majni, et al., Thin Solid Films, 1976, 38, 15

24 V.M. Mirsky, M. Riepl, O.S. Wolfbeis, Biosensors \& Bioelectron, 1997, 12, 977

25 V.M. Mirsky, M. Mass, Ch. Krause, O.S. Wolfbeis, Anal. Chem., 1998, 70, 3674

26 T.M. Bajari, K.A. Lindstedt, M. Riepl, V.M. Mirsky, J. Nimpf, O.S. Wolfbeis, H.A. Dresel, E.K.F. Bautz, W.J. Schneider, Biol. Chem., 1998, 379, 1053

27 V.M. Mirsky, Th. Hirsch, S.A. Piletsky, O.S. Wolfbeis, Angew. Chem. Intl. Ed. Engl., 38 (1999) 1108-1110, German version: Angew. Chem. 111, 1179-1181, 1999

28 M.T.A. Van der Putten, J.W.G. de L.G.J. Bakker, Fokkik, J Electrochem. SOC., 1992, 139, 3475

29 V. Popescu, Rev. Chim., 2004, 55, 797

20 V. Popescu, Rev. Chim., 2004, 55, 845

31 M.M.K.H. Ballard, L.C. Hoffman, FR Patent, 1,539,692, 1968 